\title{
Les manuscrits médiévaux témoins de lectures, éds. Catherine Croizy-Naquet, Laurence Harf-Lancner, Michelle Szkilnik
}

\section{Maria Colombo Timelli}

\section{(2) OpenEdition Journals}

Édition électronique

URL : http://journals.openedition.org/studifrancesi/5221

DOI : 10.4000/studifrancesi.5221

ISSN : 2421-5856

Éditeur

Rosenberg \& Sellier

\section{Édition imprimée}

Date de publication : 1 décembre 2016

Pagination : 497-498

ISSN : 0039-2944

\section{Référence électronique}

Maria Colombo Timelli, «Les manuscrits médiévaux témoins de lectures, éds. Catherine Croizy-Naquet, Laurence Harf-Lancner, Michelle Szkilnik », Studi Francesi [En ligne], 180 (LX | III) | 2016, mis en ligne le 01 janvier 2017, consulté le 18 septembre 2020. URL : http://journals.openedition.org/studifrancesi/ 5221 ; DOI : https://doi.org/10.4000/studifrancesi.5221

Ce document a été généré automatiquement le 18 septembre 2020.

\section{cc) (†) $\odot$}

Studi Francesi è distribuita con Licenza Creative Commons Attribuzione - Non commerciale - Non opere derivate 4.0 Internazionale. 


\title{
Les manuscrits médiévaux témoins de lectures, éds. Catherine Croizy- Naquet, Laurence Harf-Lancner, Michelle Szkilnik
}

\author{
Maria Colombo Timelli
}

\section{RÉFÉRENCE}

Les manuscrits médiévaux témoins de lectures. Études recueillies par Catherine CroizyNaquet, Laurence Harf-Lancner, Michelle Szkilnik, Paris, Presses Sorbonne Nouvelle, $2015,259 \mathrm{pp}$.

1 Ce recueil d'articles sur le livre médiéval, manuscrit et imprimé, a le mérite de prendre en compte des aspects parfois négligés, parfois passés sous silence, dans les descriptions qui accompagnent les éditions critiques, à savoir la manière dont il témoigne d'une lecture, voire de plusieurs; le centre de la réflexion se déplace en effet ici de l'objet livre au lecteur qui l'a possédé, intégré à sa bibliothèque, voire copié et illustré: autant de volets qui correspondent aux quatre parties du volume («Le lecteur dans la bibliothèque», «Le lecteur dans le scriptorium», «Le lecteur dans le cabinet de l'auteur», «Le lecteur dans l'atelier de l'enlumineur»).

2 Les deux premières contributions portent ainsi sur deux collections du dernier siècle du Moyen Âge. L'une, de Gilbert FouRNIER, évoque d'abord les règles et les conditions du prêt «extra domum» au collège de Sorbonne, pour s'attacher ensuite à ce lecteur «extraneus» que fut Simon de Plumetot; la comparaison entre les livres que ce parlementaire emprunta en 1424 et ses manuscrits personnels confirme son intérêt pour la littérature politique et en particulier pour la question des relations entre pouvoir théocratique et pouvoir royal (Ouvrir la bibliothèque. Lecteurs étrangers et lectures étrangères au collège de Sorbonne au XV siècle, pp. 17-45). L'autre, de Marie-Hélène TESNIÈRE 
, souligne la fonction des tables de matières dans certains manuscrits ayant appartenu à Charles V, permettant une lecture de consultation, éminemment sélective. En particulier, le manuscrit Besançon, BM 434, «livre d'étude du roi», est un recueil de textes en français, véritable livre d'éducation morale du prince: ses titres courants, miniatures et surtout une table générale, ont justement pour but de permettre une lecture personnelle et ponctuelle (Les manuscrits de la Librairie de Charles V ont-ils été lus? L'enseignement des tables, pp. 47-63).

3 Trois autres articles visent plutôt à montrer comment des gloses, commentaires, et même l'ordre des textes qu'ils contiennent, peuvent témoigner de lectures et d'interprétations diverses. Il en va ainsi pour les Prophetiae Merlini, énoncés cryptiques ayant inspiré de nombreux commentaires, en latin et en français, partiels ou complets, tout au long du Moyen Âge. Richard TRACHSLER signale le cas remarquable de l'iconographie du manuscrit Londres BL, Cotton Nero A IV, et souligne l'intérêt des traces de lecture et d'exégèse repérables dans les marges ou dans l'interligne d'autres copies (Du "libellus Merlini" au "livret Merlin". Les traductions françaises des "Prophetiae Merlini" dans leurs manuscrits, pp.67-87). Le recueil hagiographique présenté par Maximilian DIESENBERGER fut copié dans le monastère de Benediktbeuern en trois phases, entre le dernier quart $\mathrm{du} \mathrm{vIII}^{\mathrm{e}}$ siècle et le premier quart du siècle suivant; les modifications qu'il contient par rapport à la Table des matières prévue par le premier scribe est de fait le reflet des changements politiques en cours (Le manuscrit Bayerische Staatsbibliothek CLM 4554, témoin de lectures, pp. 89-106). La quarantaine de copies de Virgile transcrites au $\mathrm{IX}^{\mathrm{e}}$ siècle représentent de véritables "éditions scolaires»: David GANZ s'occupe en particulier du manuscrit Valenciennes, BM 407, qui contient des gloses sur quelques passages des Géorgiques et de l'Enéide (Un carolingien anonyme sur les vers de Virgile, pp. 107-115).

4 Le groupe le plus consistant d'articles porte sur le rapport entre manuscrit et auteur, à partir du moment - en gros, le XIII ${ }^{\mathrm{e}}$ siècle - où cette notion s'affirme définitivement. Milena MIKHAÏLOVA-MAKARIUS attire ainsi l'attention sur les recueils d'auteur, en étudiant spécialement les cas de Chrétien de Troyes dans le ms fr. 1450 de la BnF, Adenet le Roi (Arsenal 3142), Marie de France (Harley 978), Robert de Blois (Arsenal 5201), Adam de la Halle (Arsenal 25566), Rutebeuf (fr. 837), recueils dont se dégagent de véritables biographies littéraires (Cil qui fist...: l'auteur présenté à ses lecteurs. Les manuscrits d'auteur de la seconde moitié du XIII siècle, pp.119-134). Une réflexion analogue, sur l'auteur comme «facteur d'unification» de certains manuscrits, est proposée par Clotilde DAUPHANT, qui présente les exemples de Machaut et de Froissart responsables respectivement du ms fr. 1584 et des mss fr. 830 et 831 de la BnF, puis des œuvres d'Eustache Deschamps copiées par Raoul Tainguy (fr. 840), véritable éditeur scientifique avant la lettre (Qui vouldra de mes choses sçavoir: Lire Machaut, Froissart et Deschamps dans leurs cuvres complètes, pp.135-150). Sylvie LEFÈVRE revient sur la tradition manuscrite de Jean de Saintré, et notamment sur le statut du célèbre manuscrit F, dont le caractères (partiellement) autographe est toujours sujet à caution. Elle insiste surtout sur l'intérêt de la division en chapitres, qui n'existe pas dans toutes les copies conservées et qui n'est même pas homogène dans $F$, mais qui doit nous questionner quant à l'appartenance générique même du texte, roman ou «traité» (Lorsque l'auteur se relit? Antoine de La Sale et son "Jean de Saintré", pp. 151-193). La contribution de Virginie MINET-MAHY et Jean-Claude MÜHLETHALER comprend deux volets, l'un sur les traces d'une possible lecture à voix haute du célèbre Livre d'Amis de Charles d'Orléans, l'autre sur 
l'éclairage que le contexte peut jeter sur la section dite du «concours de Blois»: certains échos entre les poèmes semblent être la preuve d'un véritable jeu littéraire et d'une réflexion sur la création poétique noués dans l'ensemble du manuscrit (De la lecture à la performance: le "Livre d'amis" de Charles d'Orléans, pp. 175-196).

Deux articles concernent le rapport entre texte et iconographie. Marina TRAMET examine deux manuscrits du Roman de la Violette peu connus en raison de leur intérêt limité pour l'édition du texte: $C$, manuscrit bourguignon illustré, et $\mathrm{B}$, qui contient trois insertions lyriques supplémentaires. L'un et l'autre témoignent d'une réception possible du roman de Gerbert de Montreuil: si les enluminures du manuscrit $\mathrm{C}$ semblent recentrer l'attention sur les deux protagonistes, le manuscrit B met plutôt l'accent sur la morale à tirer du roman (Conservatisme et innovation dans les manuscrits du "Roman de la Violette" de Gerbert de Montreuil, pp. 199-214). Florence BOUcHET s'intéresse enfin à un incunable parisien, illustré, du Roman de la Rose, où elle souligne la présence de «titres de chapitres» versifiés, de didascalies signalant les prises de parole des personnages, et de bois gravés. Tout ces apparat témoigne d'interprétations et de lectures superposées, en partie dérivées de la tradition manuscrite et imprimée précédente (Le lecteur du "Roman de la Rose", entre apprentissage et polémique: texte et image dans l'incunable Paris 114 de la Bibliothèque municipale de Toulouse, pp. 215-232 + 8 reproductions en noir et blanc).

Éléments de bibliographie aux pp. 241-249 et Index (des auteurs et des titres) aux pp. 251-258. 